IZA DP No. 9894

Improving the Peer Review Process:

A Proposed Market System

Paul Frijters

Benno Torgler

April 2016 


\title{
Improving the Peer Review Process: A Proposed Market System
}

\author{
Paul Frijters \\ University of Queensland \\ and IZA \\ Benno Torgler \\ Queensland University of Technology \\ and CREMA \\ Discussion Paper No. 9894 \\ April 2016 \\ IZA \\ P.O. Box 7240 \\ 53072 Bonn \\ Germany \\ Phone: +49-228-3894-0 \\ Fax: +49-228-3894-180 \\ E-mail: iza@iza.org
}

\begin{abstract}
Any opinions expressed here are those of the author(s) and not those of IZA. Research published in this series may include views on policy, but the institute itself takes no institutional policy positions. The IZA research network is committed to the IZA Guiding Principles of Research Integrity.

The Institute for the Study of Labor (IZA) in Bonn is a local and virtual international research center and a place of communication between science, politics and business. IZA is an independent nonprofit organization supported by Deutsche Post Foundation. The center is associated with the University of Bonn and offers a stimulating research environment through its international network, workshops and conferences, data service, project support, research visits and doctoral program. IZA engages in (i) original and internationally competitive research in all fields of labor economics, (ii) development of policy concepts, and (iii) dissemination of research results and concepts to the interested public.
\end{abstract}

IZA Discussion Papers often represent preliminary work and are circulated to encourage discussion. Citation of such a paper should account for its provisional character. A revised version may be available directly from the author. 


\section{ABSTRACT \\ Improving the Peer Review Process: A Proposed Market System}

The current peer review system suffers from two key problems: promotion of an in-crowd whose methods, opinions and innovations it protects; and failure to represent the opinions and interests of non-peer clients. As a result, whole disciplines orient themselves toward navel-gazing research questions of little import to society or even science as a whole, and new methods and concepts must be unusually persuasive to break through. We thus suggest a more efficient and integrity-preserving system based on an open two-sided market in which buyers and sellers of peer review services would both be subject to a set of recursive quality indicators. We lay out key features we think would be important to reduce the opportunities for gaming and that improve the signals about the societal value of a contribution. Our suggestions include a level of reward offered by the author of a paper to get refereed and a level of desired quality of the referee. They include randomly selecting from a group of referees that express a willingness to accept the offered contract. They include the possibility that papers are put up by non-authors for peer-review for assessment on different criteria, such as societal relevance. And they finally include the possibility that referee reports themselves become refereed by other referees. What we envisage is that such an open market in which all elements are subject to peer review will over time lead to specialized reviewers in different criteria, and more useful signals about the nature and quality of any individual piece of work. Our incentivized market set-up would both professionalize the peer review process and make it completely transparent, an innovation long overdue.

JEL Classification: A14, A11, Z00, D72, L30

Keywords: peer-review, public relevance, transparency, two-sided markets, market design

Corresponding author:

Paul Frijters

University of Queensland

Level 6, Colin Clark Building (39)

St Lucia, Brisbane, Qld 4072

Australia

E-mail: p.frijters@uq.edu.au 
Although peer review has long been the primary mechanism for maintaining high scientific standards and guaranteeing advancement in knowledge and learning, the system has largely been an amateur process ${ }^{1}$, which is coming under increasing stress ${ }^{2}$. The two key problems with the system are promotion of an in-crowd and failure to represent the opinions and interests of non-peer clients such as government and industry. It achieves the first by protecting the methods, opinions, and innovations of those with inside access while barring outsiders and coercing intensively socialized juniors into towing the accepted line ${ }^{3}$. As a result, new methods and concepts must be unusually persuasive to break through into top journals. At the same time, the failure to represent outside interests leads whole disciplines to orient themselves toward navel-gazing research questions of little import to society or even science as a whole. Admittedly, excluding the interests of society from article evaluation allows scientists to “dream out loud” without fear of societal disapproval, which sometimes generates discoveries not immediately recognized as useful but of enormous long-term social benefit. Nevertheless, given the huge societal resources flowing into science, the question of whether society receives valuable innovative research in return is more salient than ever.

Yet attempts to improve the peer review system have been consistently unsuccessful ${ }^{4}$, making the current system simply a better choice than its failed alternatives ${ }^{5}$. We therefore suggest a new system that is fast, efficient, reliable, fair, integrity preserving, and gaming resistant; namely, an open two-sided market of buyers and sellers of peer review services that overcomes present shortcomings by using a sophisticated system of recursive quality indicators attached to both authors and peer reviewers. In such a system, authors would post their articles on the peer review market as unreviewed manuscripts (with full disclosure of name and affiliation) and then decide on the number of credit points they are willing to offer to receive ratings on different aspects (e.g., "academic quality," "methodological soundness," "societal relevance,” “innovation,” “creativity”). They would also be able to specify a minimum level of reviewer quality for any of these aspects (i.e., a fee per unit of reviewer quality for each aspect to be rated). Newcomers to the system would start out with zero reviewer credit points, giving them two options for article review: to earn reviewer credit points from scratch or buy them directly from the nonprofit organization managing the peer review market system. Assuming a greater interest in earning credit points by reviewing than in paying for reviews, "reviewer quality ratings" would be set based on a multifactor formula covering such characteristics as area-specific quality, weighted ratings of previous papers, and referee reports. The precise formula would of course be crucial to the system and thus subject to broad discussion. 
Once authors have stipulated their desired quality ratings, reviewers with appropriate qualifications in the specified area could decide whether to accept the offer on a first-comefirst-served basis, which would discourage the organization of new cliques and gaming of the system: in order to prevent gaming by a reviewer and an author who know each other, there would be some random delay between posting an article and potential reviewers seeing it; potential reviewers would only see broad indicators of the articles for review; and there would be random clearing in the sense that the allocated reviewers are randomly chosen from the set of suitable reviewers who expressed an interest in reviewing the article (this copies the norm in financial markets). Authors would then be more inclined to write for the entire field rather than for small groups within it. Once the number of reviewers for each aspect was sufficient to ensure reliable evaluation, all reviewers would be notified of their obligation to deliver their reviews within a certain time period. At this point, the reviewer credit points would be frozen in expectation of a successful trade.

The reviewers would then deliver their reports, which would be credited to their names and entirely visible to everyone on the market, together with their own reviewer quality ratings. On delivering their reports, the reviewers would receive credit points to be used either to pay for reviews of their own papers or exchanged for cash from the managing organization. The system would thereby allow and even encourage professional referees whose only job would be review, which would address the emerging problem of peer reviewers being overwhelmed by the increasing number of journal submissions ${ }^{6}$. Given that professionalization has already been successful at the editorial level, there is no reason it should stop there.

The system would also improve review quality by exposing referee ratings to a secondary market, that of reviewer quality ratings. The visible signals, therefore, would not only be the referee reports and article ratings but also the weighted ratings for each reviewer, which would be continuously updated to reflect current market quality. Hence, both articles and referee reports would be subject to peer review, which would be the only means of either earning high ratings, which should reduce the criticism that open reviews are not as brutally honest as anonymous ones ${ }^{7}$. It would also ensure tactful and constructive reviews ${ }^{8}$ because biases such as vested interests would be easily unmasked.

Above all, the setting up of a peer review market would facilitate the involvement of far more agencies and actors than is currently possible. Logically, such set-up could best be achieved by agencies already in the research index game, which already have much of the infrastructure and an established network of associated organizations and authors in place. Journals, of course, would have an interest in protecting their status quo, but this new approach 
would not mean the end of journals per se. Rather, by selecting the most potentially impactful articles from the peer review market (subject to author approval), journals would act as attention focusers, information filters, and reputation generators. Such selection is in any case the most important of an academic journal's functions, one that is becoming especially crucial as over million new articles appear each year ${ }^{9}$. A peer review market would ease the journals' administrative burden while broadening the number of arbiters of academic merit. It might also encourage editors to meet previous requests that they take a more long term and broader view and be more open to new approaches ${ }^{10}$.

A market set-up would not only professionalize the peer review process but also make it completely transparent ${ }^{4}$, which should lead to higher quality peer reviews while hampering the formation of hidden cliques. Half-way solutions, on the other hand, are unlikely to succeed. For example, in 2006, Nature experimented with open peer review by offering authors the option of having their manuscript placed on an open server for community commentary. Not only were $95 \%$ of the authors uninterested, but only a limited number of comments were logged (http://www.nature.com/nature/peerreview/debate/ nature05535.html). The problem with this approach was its lack of incentivization. The market proposed here, in contrast, would solve many such issues, improve the process, and provide long overdue innovations.

1. Groves, T. Quality and Value: How Can we Get the Best Out of Peer Review?, Nature http://blogs.nature.com/peer-to-peer/2006/06/quality_and_value_how_can_we_g.html. (2006).

2. Alberts, B., Hanson, B., Kelner, K. L. Reviewing Peer Review, Science 321, 15 (2008).

3. Harly, D. Scholarly Communication: Cultural Contexts, Evolving Models Science 342, 80-82 (2013).

4. Couzin-Frankel, J., Secretive and Subjective, Peer Review Proves Resistant to Study Science 341, 1331 (2013).

5. Mervis, J., Peering into the Peer Review Science 343, 596 (2014).

6. Arns, M., Open Access Is Tiring Out Peer Reviewers, Nature 515, 467 (2014).

7. Koonin, E., Landweber, L., Lipman, D. \& Dignon, R., Systems: Reviving a Culture of Scientific Debate, Nature, http://blogs.nature.com/peer-topeer/2006/06/systems_reviving_a_culture_of_1.html (2006).

8. T. DeCoursey, Perspective: The Pros and Cons of Open Peer Review, Nature http://blogs.nature.com/peer-to-peer/2006/06/perspective_the_pros_and_cons.html (2006).

9. Jennings, C. G., Quality and Value: The True Purpose of Peer Review?, Nature http://blogs.nature.com/peer-to-peer/2006/06/quality_and_value_the_true_pur.html (2006).

10. Lawrence, P. A., The politics of publication, Nature 422, 259-261 (2003). 